\title{
Comorbidities in idiopathic pulmonary fibrosis: an underestimated issue
}

\author{
Antonella Caminati ${ }^{1}$, Chiara Lonati ${ }^{2}$, Roberto Cassandro ${ }^{1}$, Davide Elia ${ }^{1}$, \\ Giuseppe Pelosi ${ }^{3,4}$, Olga Torre $^{1}$, Maurizio Zompatori ${ }^{5,6}$, Elisabetta Uslenghi ${ }^{5}$ and \\ Sergio Harari $\oplus^{1,2}$
}

Affiliations: ${ }^{1}$ UO di Pneumologia e Terapia Semi-Intensiva Respiratoria - Servizio di Fisiopatologia Respiratoria ed Emodinamica Polmonare, Ospedale San Giuseppe - MultiMedica IRCCS, Milan, Italy. ${ }^{2}$ UO di Medicina Generale, Ospedale San Giuseppe - MultiMedica IRCCS, Milan, Italy. ${ }^{3}$ Dipartimento di Oncologia ed Onco-ematologia, Università degli Studi di Milano, Milan, Italy. ${ }^{4}$ Servizio Interaziendale di Anatomia Patologica, Polo Scientifico e Tecnologico, MultiMedica IRCCS, Milan, Italy. ${ }^{5}$ Dipartimento di Diagnostica per Immagini e UO di Radiologia, MultiMedica IRCCS, Milan, Italy. ${ }^{6}$ Dipartimento Universitario DIMES, Università di Bologna, Bologna, Italy.

Correspondence: Chiara Lonati, UO di Medicina Generale, Ospedale San Giuseppe - MultiMedica IRCCS, Via San Vittore 12, 20123 Milan, Italy. E-mail: chiara.lonatidamultimedica.it

@ERSpublications

The optimal clinical management of IPF is multifaceted and not only involves antifibrotic treatment. Treatment of comorbidities may help to improve quality of life and survival in IPF. The numbers of comorbidities can also affect survival. http://bit.ly/31We41O

Cite this article as: Caminati A, Lonati C, Cassandro R, et al. Comorbidities in idiopathic pulmonary fibrosis: an underestimated issue. Eur Respir Rev 2019; 28: 190044 [https://doi.org/10.1183/16000617.00442019].

ABSTRACT Idiopathic pulmonary fibrosis (IPF) is a progressive and fibrosing lung disease with a poor prognosis. Between $60 \%$ and $70 \%$ of IPF patients die of IPF; the remaining causes of death may be due to comorbidities occurring in this ageing population. Interest in the role played by comorbidities in IPF has increased in the past few years. The optimal clinical management of IPF is multifaceted and not only involves antifibrotic treatment, but also vaccinations, oxygen supplementation, evaluation of nutritional status as well as psychological support and patient education. Symptom management, pulmonary rehabilitation, palliative care and treatment of comorbidities represent further areas of clinical intervention. This review analyses the major comorbidities observed in IPF, focusing on those that have the greatest impact on mortality and quality of life (QoL). The identification and treatment of comorbidities may help to improve patients' health-related QoL (i.e. sleep apnoea and depression), while some comorbidities (i.e. lung cancer, cardiovascular diseases and pulmonary hypertension) influence survival. It has been outlined that gathering comorbidities data improves the prediction of survival beyond the clinical and physiological parameters of IPF.

\section{Introduction}

Idiopathic pulmonary fibrosis (IPF) is a progressive and fibrosing lung disease with an average survival of 3-5 years from the time of diagnosis [1]. Although it is not a neoplastic condition, the average survival can be similar or even worse than in many tumours $[2,3]$. Between $60 \%$ and $70 \%$ of IPF patients die from causes directly related to IPF $[4,5]$; the remaining causes of death may be due to comorbidities occurring particularly in this older population. The great research effort made in the past 20 years has led to the approval of two molecules for the treatment of IPF (pirfenidone and nintedanib), a previously "orphan"

Provenance: Publication of this peer-reviewed article was sponsored by Boehringer Ingelheim, Germany (principal sponsor European Respiratory Review issue 153).

Received: 30 April 2019 | Accepted after revision: 16 Aug 2019

Copyright $\odot$ ERS 2019. This article is open access and distributed under the terms of the Creative Commons Attribution Non-Commercial Licence 4.0. 
disease with no treatment option [6-13]. However, this only represents a first step in the treatment of IPF. Today we do in fact have a therapy for these patients: although it is not a cure, the two drugs can slow down the progression of the disease by limiting functional loss in these patients. Moreover, these therapies are reserved for cases with well-defined functional parameters. Patients with advanced disease currently have no therapeutic options $[14,15]$. Reasonable objectives may be to slow down the progression of the condition (which we can achieve through new antifibrotic therapies), to improve patients' symptoms (through palliative care), to prevent what is preventable (trying to avoid possible risk factors such as smoking, gastro-oesophageal reflux (GOR) and air pollution) and to manage the comorbidities of these patients in the best possible way $[16,17]$. The incidence and prevalence of IPF tends to increase with age $[18,19]$. Comorbidities in this clinical context are varied, and can significantly affect the survival, prognosis and quality of life (QoL) of these patients [20-24].

The large prospective multicentre randomised studies conducted in recent years have significantly increased our knowledge and understanding of the natural history of IPF. However, the inclusion and exclusion criteria of the trials led to the enrolment of patients without major comorbidities, thus moving away from the enrolment of real-life patients with IPF [25].

When we study comorbidities in this disease we must therefore consider studies other than the large randomised clinical trials. Several recent studies have reported a considerable degree of variability and differences in the prevalence of comorbidities; this is highly dependent on how the studies were conducted. Many of these trials derive from the retrospective analysis of the experience of single centres $[21,23]$, others from the prospective or retrospective analysis of national registries $[21,26,27]$ and others from the analysis of administrative datasets [28, 29]. It is therefore clear that the results of such methodologically different studies are not comparable, at least as far as the prevalence and incidence of comorbidities are concerned. In general, studies based on administrative datasets report a lower prevalence of comorbidities than retrospective studies or registers because of an underestimation issue related to coding $[20,30]$. These differences are also influenced by features such as length of the observation period and sample size [20,30].

The objective of this review is to analyse the major comorbidities observed during IPF, focusing on those that have the greatest impact on mortality and QoL of patients, with many of these representing the "IPF comorbidome" [23].

\section{Comorbidities and IPF}

Different numbers and types of comorbidities may be observed in patients with IPF. In a retrospective monocentric study on 272 patients with IPF, $12 \%$ of the sample had no comorbidities, $58 \%$ had one to three comorbidities and $30 \%$ had four to seven comorbidities [23]. The median survival according to the frequency of comorbidities ranged from 66 months for patients not having comorbidities to 48 months for those who had one to three comorbidities and to 35 months for those who had four to seven comorbidities [23]. In this study, cardiovascular disease and lung cancer were found to be the comorbidities that had the greatest impact on mortality [23]. Another recent monocentric study conducted in Denmark on 121 patients identified cardiovascular disease, depression, hypertension and diabetes mellitus as the most common comorbidities in patients with IPF [21]. Similar data also emerged from the German INSIGHTS-IPF registry that since 2012 prospectively collected data on more than 500 patients from 19 centres [22]. Highly conflicting data emerged with respect to the prevalence of lung cancer in patients with IPF, ranging from $1 \%$ as reported in the INSIGHTS-IPF registry [22] to $15 \%$ according to Kreuter et al. [23] and to 6\% as reported in the Danish trial [21]. In another study, 20.4\% of 103 IPF patients developed lung cancer during an observation period of up to 10 years, with an increasing cumulative incidence as the follow-up progressed [31]. The differences could have been due to the fact that patients with IPF and lung cancer are treated mainly by oncologists and not by pulmonologists, and these patients never enter a registry database. Differences in lifestyle and diet in different countries, and differences in smoking histories, sample size, length of observation period and how patients are studied, may also arise. GOR and reflux symptoms are other comorbidities characterised by an extremely variable prevalence, ranging from $0 \%$ to $94 \%$ depending on the study and type of assessment $[20,21,32,33]$.

Some comorbidities observed during IPF share the same risk factors, e.g. lung cancer, chronic obstructive pulmonary disease (COPD) and cardiovascular diseases related to cigarette smoking. Another association might be the process of ageing, which is closely connected to telomerases. Mutations in TERT (telomerase reverse transcriptase) or TERC (telomerase RNA component) and telomere shortening are involved in the pathogenesis of IPF [3, 34], but also of cancer [35] as well as of emphysema [36]. This gave rise to the hypothesis that IPF and some of its comorbidities are a "combined" disease/syndrome of ageing [23, 37]. Other common pathogenetic pathways between IPF and cancer may exist and have been described [3]. Some comorbidities may be involved in the development of IPF: diabetes may influence the progression or 
the beginning of IPF through hyperglycaemia-associated pulmonary inflammation [38, 39]; GOR could lead to chronic inflammation through repetitive microaspiration events and may finally lead to fibrotic evolution [40].

\section{Emphysema and COPD}

The vast majority of patients with IPF are smokers or ex-smokers. It is therefore not surprising that patients with IPF may also have symptoms of emphysema and/or COPD. These aspects are more obvious from the radiological perspective than from the functional point of view. About $30 \%$ of IPF patients have concurrent pulmonary emphysema, including $8-27 \%$ of patients with $10 \%$ emphysematous changes throughout the lungs, predominantly in the upper lobes [41-43]. However, in several studies the detection of emphysema/COPD varied from $6 \%$ to $67 \%$ [20]. When emphysema is a relevant component of the condition, it is referred to as "combined pulmonary fibrosis emphysema" (CPFE) seen as a distinct phenotype of IPF [44]. Patients with CPFE are generally middle-aged males, strong smokers with high-resolution computed tomography (HRCT) showing typical or atypical fibrosis at the base of the lung and emphysema in the upper lobes [44]. Respiratory function tests indicate that lung volumes are preserved (due to the opposite effect that fibrosis and emphysema have on lung volumes), while at the same time an extremely severe and disproportionate reduction of the diffusing capacity of the lung for carbon monoxide $\left(D_{\mathrm{LCO}}\right)$ can also be observed $[44,45]$. These patients are severely hypoxaemic and usually experience major desaturations during the 6-min walk test. CPFE is also associated with the frequent occurrence of pulmonary hypertension and lung cancer as well as with a worse prognosis compared with pure IPF $[44,45]$. Changes in forced vital capacity (FVC) over time in patients with CPFE are less reliable in assessing disease progression; the variation in forced expiratory volume in $1 \mathrm{~s}$ is a more accurate and reliable indicator in these patients [46-49]. It is still uncertain whether pulmonary fibrosis and emphysema are two different diseases simply associated with cigarette smoking or if instead they represent a distinctive phenotype of a subset of patients [50]. The patients in whom the amount of emphysema outperforms that of fibrosis are generally not included in clinical trials because of their different functional performance compared with patients with IPF alone. A post hoc analysis of the data from the INPULSIS trial reported that the effect of nintedanib was the same in patients with and without emphysema [51]. To date, it is unclear whether nintedanib and pirfenidone also work in the same way in patients with CPFE. Bronchodilator therapy and pulmonary rehabilitation may be empirically prescribed and may play a role [52].

\section{Pulmonary hypertension}

Pulmonary hypertension is currently defined as mean pulmonary arterial pressure (mPAP) $\geqslant 20 \mathrm{mmHg}$ at right heart catheterisation (RHC) [53-55]; it is a common complication of IPF, especially during its progression and in the advanced stages of the disease. The true prevalence of pulmonary hypertension in IPF is difficult to ascertain, as estimates are very different and depend on case-finding methodology and the IPF population studied. Insurance claims data report a very low prevalence of pulmonary hypertension (3\%) in IPF patients [28]. A prevalence of $29-46 \%$ has been reported in studies in which RHC has been carried out (RHC being the gold standard for the diagnosis of pulmonary hypertension) [53-64]. A prevalence as high as $84 \%$ was reported in patients with advanced disease investigated through transthoracic echocardiography (a commonly used procedure to screen for pulmonary hypertension [56, 65]), although it is likely that the prevalence is overestimated due to the high variability of this method. Approximately $30-50 \%$ of patients with advanced IPF do develop pulmonary hypertension [20]. The prevalence of pulmonary hypertension at diagnosis depends on the severity of IPF and possibly also on the presence of other comorbidities, e.g. sleep apnoea, thromboembolic/cardiac diseases and COPD. The presence of pulmonary hypertension should always be suspected in patients with severe hypoxia or subjects who become desaturated during the 6-min walk test in a way that is disproportionate to their functional status and also when $D_{\text {LCO }}$ values are disproportionately low. From the clinical perspective, signs of right heart failure may become evident. Chest CT may show enlargement of the pulmonary arterial diameters, although, especially in IPF patients, imaging studies may overestimate the presence of pulmonary hypertension (probably due to traction phenomena exerted on the vasculature by fibrotic tissue). In a number of studies, pulmonary hypertension detected through echocardiographic scans or by RHC with different cut-off points was reported to be associated with an increased risk of death $[44,56,66$, 67]. A three-fold increase in mortality was proven in patients with pulmonary hypertension, especially when systolic PAP exceeds $50 \mathrm{mmHg}$ at echocardiography [56]. The presence of pulmonary hypertension impacts not only on survival, but also on exercise capacity and QoL. There is currently no indication to treat pulmonary hypertension in patients with IPF. Studies conducted in recent years with different drugs commonly used in primary pulmonary hypertension (bosentan, ambrisentan, macitentan and riociguat) have all given negative results in terms of slowing the progression of the disease in patients with IPF without pulmonary hypertension [68-70] and in modifying the haemodynamic setting in patients with 
concomitant pulmonary hypertension [71-73]. Therefore, patients with pulmonary hypertension in IPF are a group of subjects with high and unmet medical needs [74]. A study on sildenafil in patients with advanced disease (defined as $D_{\mathrm{LCO}} \leqslant 35 \%$ predicted), although it did not reach the primary end-point, did report encouraging results in the secondary end-points: improvement of dyspnoea, QoL, $D_{\mathrm{LCO}}$ and oxygen saturation [75]. In a subsequent pre-specified analysis, it has been demonstrated that sildenafil works well and preserves exercise capacity only in IPF patients who have right-sided ventricular dysfunction [76]. On the basis of this observation, further studies were conducted using a combination of sildenafil and pirfenidone or nintedanib in patients with advanced IPF and pulmonary hypertension. The association of sildenafil and nintedanib did not provide a significant benefit on QoL compared with nintedanib alone (a change in the St George's Respiratory Questionnaire was the primary end-point and dyspnoea was a secondary end-point) [77]. The study on the combination of sildenafil and pirfenidone in patients with advanced IPF is still ongoing. Patients with $\mathrm{mPAP} \geqslant 20 \mathrm{mmHg}$ on RHC or an echocardiogram peak tricuspid valve regurgitation velocity $\geqslant 2.9 \mathrm{~m} \cdot \mathrm{s}^{-1}$ are considered to be affected by intermediate/high likelihood of pulmonary hypertension and will be therefore considered eligible for this study (ClinicalTrials.gov identifier NCT02951429). A $D_{\text {LCO }} \leqslant 40 \%$ predicted was selected as part of the inclusion criteria to increase the likelihood of the study to include patients with pulmonary vasculopathy and a risk of pulmonary hypertension. We are now waiting for the results of this trial [78].

\section{Lung cancer}

We have already mentioned the variable incidence and prevalence of lung cancer in patients with IPF that were reported in several papers (figure 1) [20]. Previous studies have revealed a high incidence of lung cancer in IPF [31, 79-81] and a likely increase in the annual risk of lung cancer that appears to rise over the years following diagnosis [31]. Cell senescence, genetic and epigenetic alterations, abnormal expression of microRNAs, delayed apoptosis, and activation of specific transduction pathways have been observed in both IPF and cancer pathogenesis [3, 82]. An even higher incidence has been reported in CPFE [83, 84]. TOMASSETTI et al. [85] found that lung cancer in IPF patients has a significant negative impact on survival. They demonstrated that the difference in mortality seen in their study was not due to the progression in IPF, but mostly caused by the worsening of lung cancer and treatment-related complications [85]. The surgical management of early lung cancer can be curative, but it is encumbered by increased mortality and by acute exacerbation episodes (reported in $7-32 \%$ of patients) [86-90], which can also occur following chemo- and radiation therapy [31, 84, 91, 92]. Antiproliferative effects and antitumor activity of pirfenidone and nintedanib may have a synergistic effect with current chemotherapeutic regimens, but further studies are needed $[3,93,94]$. A recent study suggests that pirfenidone therapy reduces the incidence of lung cancer [95]. Although there are no reference guidelines, annual lung cancer screening with low-dose CT in high-risk patients with IPF, especially those with CPFE and/or a heavy smoking history, could be considered [65,96]. Clinicians should also consider CT examination in patients who show clinical deterioration despite stable pulmonary function or who develop new atypical symptoms in IPF.

\section{Sleep apnoea}

Recently, several studies have focused on the relationship between sleep apnoea and IPF, frequently reporting moderate-to-severe obstructive sleep apnoea (OSA) in IPF patients (defined by an apnoeahypopnoea index $>15$ events $\cdot h^{-1}$ ) [97-103]. The relationship between IPF and OSA is very complex. From a pathophysiological viewpoint, it is known that a reduction in lung volume leads to instability of the

FIGURE 1 Left lung cancer in a patient with idiopathic pulmonary fibrosis.

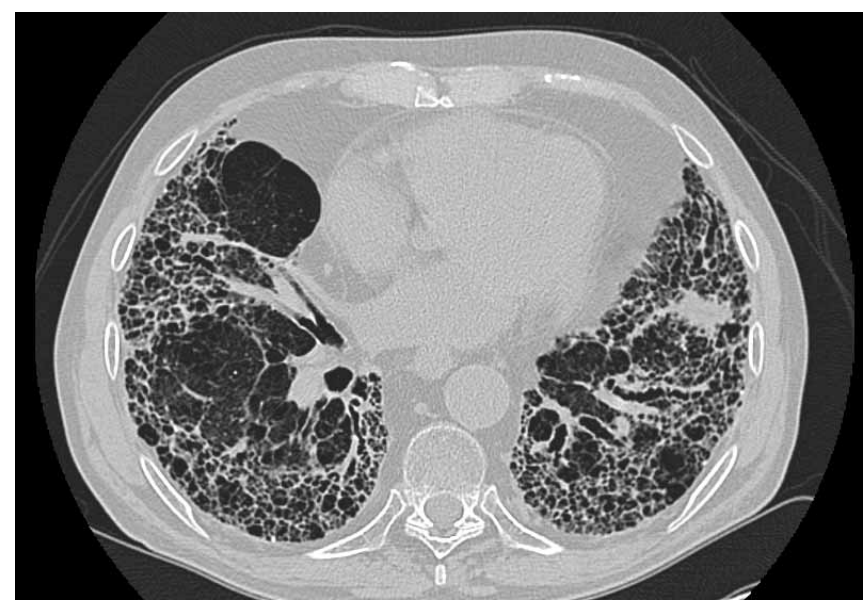


upper airways and therefore the restrictive condition that is typical of IPF can in itself support the development of OSA [104, 105]. However, OSA favours episodes of GOR, which can in turn cause inflammation and encourage the development of pulmonary fibrosis [106], and episodes of intermittent nocturnal hypoxaemia, which are associated with an increase in oxidative stress; both of these mechanisms can foster the emergence of pulmonary fibrosis [107]. In a recent prospective French study, moderate-to-severe OSA was frequently detected at the time of IPF diagnosis (62\% of cases), while cardiovascular comorbidities, particularly ischaemic heart disease (IHD), were more frequently found in IPF patients with severe OSA than in IPF patients with no or mild-to-moderate OSA. The presence of moderate-to-severe coronary artery calcifications on HRCT was strongly associated with severe OSA [108]. Previous studies reported a higher prevalence of IHD in IPF patients than in matched COPD or emphysema patients, independently of common coronary artery risk factors [109-113]. The presence of significant coronary artery disease at the time of IPF diagnosis does influence both prognosis and outcome [112]. Polysomnography is currently used in a very limited number of IPF patients ( $3 \%$ of subjects in a retrospective study) [97]. Untreated OSA may result in nocturnal oxygen desaturation episodes, which are associated with worsening of survival [114]. Nocturnal hypoxaemia is closely related to increments in right ventricular systolic pressure values associated with increased pulmonary hypertension $[114,115]$. To detect occult OSA, nocturnal polysomnography should be performed at the time of IPF diagnosis, especially when moderate-to-severe coronary artery calcifications are seen on HRCT images [108]. The use of continuous positive airway pressure results in significant improvements in activities of daily living, quality of sleep, QoL and survival [100]. This observation provides the first evidence that the treatment of some comorbidities could affect the outcome and prognosis in IPF patients. However, the impact of OSA on survival is still not really clear and needs to be explored further in prospective studies.

\section{Cardiovascular conditions and pulmonary embolism}

A number of cardiovascular comorbidities have been reported in several studies: systemic arterial hypertension, arrhythmias/atrial fibrillation, heart failure, IHD, cerebral ischaemic events and strokes. The reported prevalence varies according to the type of study and the population investigated. The frequency of cardiovascular comorbidities is, however, higher than in the general population and even than in patients with COPD [110, 112]. IHD was the most frequently reported cardiovascular comorbidity, characterised by extremely variable values ranging from $3.2 \%$ in a study based on administrative data (from medical claims in the USA) to $68 \%$ found in patients undergoing cardiac catheterisation carried out for their inclusion in the waiting list for lung transplantation (considering both significant and nonsignificant coronary heart disease) [20]. In a group of 73 patients with IPF, $18 \%$ of them had an indication of coronary revascularisation or a significant coronary disease defined as a stenosis $>50 \%$ of a great coronary vessel as detected by cardiac angiography [112]. The recognition of coronary calcifications at chest CT may represent a valuable noninvasive screening method for the identification of coronary heart disease [116]. The recent study by KREUTER et al. [23] reports the presence of cardiovascular comorbidities in $78 \%$ of patients. IHD is associated with a worse prognosis in patients with IPF $[112,117,118]$; in a Finnish study it was found to be the second most common cause of death in patients with IPF [119].

In patients with IPF, reduced mobility and the presence of a pro-coagulant state may also promote episodes of deep vein thrombosis and pulmonary embolism (figure 2) [110, 120, 121].

In an American retrospective study, the incidence of pulmonary embolism reported in IPF patients was almost three times higher than in the subjects without IPF [28]. Therefore, pulmonary embolism should be excluded in patients with progression of symptoms and stable pulmonary function. KuBO et al. [122] published an open-label randomised trial of prednisolone plus anticoagulant therapy versus prednisolone alone in IPF patients and observed a significant reduction in the secondary end-point of IPF acute exacerbation-related mortality in patients treated with anticoagulants. Treating a hypercoagulability state in IPF may improve survival, as indicated by this encouraging study [122]. However, a placebo-controlled clinical trial on warfarin failed to meet its end-point, and demonstrated lack of benefit and increased mortality in the treated arm [123]. The results of this trial suggest that anticoagulant therapy administered specifically for treatment of IPF may be associated with a negative outcome [123]. More recent studies suggest that anticoagulant therapy used for non-IPF indications may have negative effects in IPF patients $[124,125]$.

\section{GOR disease}

Both symptomatic and asymptomatic GOR are commonly observed in patients with IPF; studies published a few years ago suggested that microaspiration events could be the cause of repetitive lung damage, thereby possibly playing a role in the pathogenesis of the disease [106]. Pepsin, a gastric aspiration marker, was retrieved from the bronchoalveolar lavage fluid of patients with stable IPF [126]. The simultaneous presence of IPF and GOR was identified in $60 \%$ of cases, but studies also including oesophageal pH-metry 

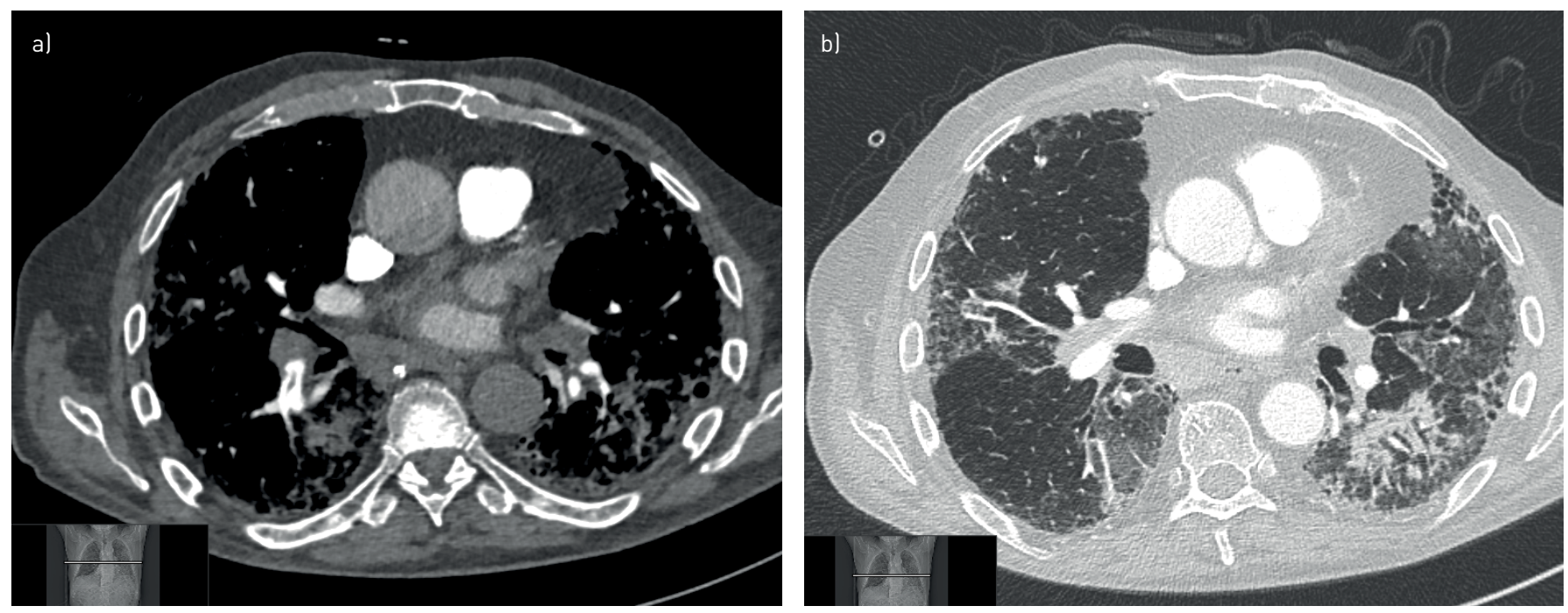

FIGURE 2 Right pulmonary embolism in a patient with idiopathic pulmonary fibrosis. a) Mediastinal window. b) Parenchymal window.

reported a prevalence $>80 \%[20,127,128]$. The possible pathogenetic role of microaspiration events is, however, questioned by the fact that while GOR is a frequently occurring clinical condition, IPF is relatively rare $[126,127,129,130]$. More recent studies have shown that patients with GOR have a better survival than subjects who do not have reflux [23, 131, 132]. This particular association may be due to an earlier IPF diagnosis in patients symptomatic for GOR [23, 132], to the identification of a particular endotype of IPF patients with a better prognosis or to a protective effect of antireflux therapy [23, 131-133]. The role of antireflux and anti-acid therapy is still controversial: use of anti-acid medication has been associated with a slower decline in FVC and improved survival [23, 131], as well as fewer exacerbations in patients with IPF [32]. Another study demonstrated that the use of anti-acid medications is not associated with a more favourable course of the disease $[134,135]$. The use of anti-GOR agents can worsen the prognosis and increase respiratory infections in patients with advanced IPF (particularly with FVC $<70 \%$ predicted) [23, 136]. Microaspiration events have been associated with episodes of acute exacerbation of IPF and may represent a trigger for these acute deterioration events [126]. Anti-acid drugs are not antireflux treatments and only act against the acidic components of reflux. Moreover, a cough trial with proton pump inhibitors showed that proton pump inhibitors increase the nonacidic components of reflux [137]. A recently published pilot trial on omeprazole in IPF demonstrated that omeprazole is well tolerated; a small excess of lower respiratory tract infection was evidenced together with a minor reduction in FVC associated with use of omeprazole [138]. In order to give a definitive answer on the effects of GOR therapy in patients with IPF, further prospective, randomised studies are needed to shed light on this specific aspect. Although antireflux surgery has controversial effects and should not be performed routinely, it may nevertheless be considered in selected IPF cases. This specific treatment has been recently investigated in a prospective phase II study demonstrating that laparoscopic antireflux surgery is a safe and well-tolerated procedure in patients with IPF and abnormal acid GOR [139].

\section{Anxiety and depression}

Although patients with IPF often show symptoms of anxiety and depression, these clinical signs have not been duly appreciated. The prevalence of anxiety and depression ranges from $30 \%$ to $50 \%$ and $20 \%$ to $30 \%$, respectively [20]. Anxiety and depression are not directly related to the functional status of patients, but the presence and worsening of dyspnoea as well as the progression of the disease do constitute aggravating factors. These two comorbidities have a significant impact on patients' QoL. The importance of depression and anxiety in COPD, as well as in other chronic respiratory diseases, is well known. Depression and anxiety are commonly observed in patients with COPD [140-142], and have an adverse influence on the course of the condition: these symptoms cause an increase in dyspnoea, and in physical disability and mortality, as well as a decrease in exercise tolerance [143]. In a recent study, IPF patients with depression were found to have a reduced QoL compared with those without depression [144]. The management of depression did not therefore influence mortality, but may be of primary importance in improving QoL in patients with IPF [144]. Recent studies have demonstrated that pulmonary rehabilitation programmes including educational approaches, disease management strategies and physical activities do significantly improve exercise capacity, dyspnoea and QoL in patients with IPF [144-146]. 
Subjects with IPF could benefit from cognitive behavioural therapy and counselling by qualified healthcare specialists. Further research is required to determine whether the psychological approach and pharmacological treatment for depression and anxiety can improve health outcomes (QoL, mortality and hospitalisation) in patients with IPF [144]. According to the recent published TORVAN study, depression is a comorbidity with real impact in the context of IPF [132].

\section{Comorbidities and survival}

Comorbidities are very common in IPF and a number of them have been found to be associated with survival in IPF (i.e. lung cancer, pulmonary hypertension and cardiovascular diseases) [57, 80, 84, 109, $112,147]$. However, researchers have not yet estimated the potential of these comorbidities for improving the prediction of survival in IPF beyond the demographic characteristics and the measures of disease severity (i.e. pulmonary function). Recently published research has developed and validated the first-ever clinical prediction model and an index point score (called the TORVAN model and index, similar to the GAP (Gender-Age-Physiology) model and index) for all-cause mortality in IPF which includes the comorbidities that are considered as variables [132]. TorRISI et al. [132] outline that the inclusion of comorbidities increased the possibility of predicting the survival potential beyond the basic physiological and functional data. Relatively few comorbidities influenced the prediction of survival, while sex became a less important prognostic indicator when viewed within the context of comorbidities [132]. The inclusion of comorbidities improved the prediction of survival, with a similar predictive performance in two independent patient cohorts. Risk stratification by this index may improve both the clinical real-life approach and the design of future clinical studies.

\section{Conclusions}

Comorbidities are commonly found in elderly patients with IPF and many of them can influence survival, such as lung cancer, pulmonary hypertension and cardiovascular diseases. The true role of comorbidities in the prognosis and survival in IPF is unknown. Data exploring their impact are limited and sometimes conflicting, probably due to the small number of patients involved and to the different definitions used to describe the individual comorbidities. The prevalence and severity of comorbidities are likely to further increase as a consequence of the improved survival in IPF patients due to the introduction of new antifibrotic treatments in clinical practice.

It is of paramount importance that clinicians understand the magnitude and significance of comorbidities in IPF. There is increasing evidence that the early diagnosis and treatment of comorbidities is an important tool together with the treatment of IPF itself. Treatment of comorbidities may improve QoL in IPF patients. Some possible strategies for the management of comorbidities in IPF include changes in lifestyle, treatment of symptomatic GOR and sleep apnoea, identification of cardiovascular risk, quitting smoking, and prescription of long-term oxygen therapy when indicated. Pulmonary rehabilitation can also have a positive impact on depression, anxiety, cardiovascular diseases and QoL [148, 149]. Palliative care in patients with advanced disease or poor symptom control is another important issue to consider [150].

We are increasingly moving towards the concept of personalised medicine in IPF patients. Timely detection, comprehensive evaluation of the patient as a whole and effective treatment of comorbidities in IPF should be areas of future research that could indeed improve the global management and QoL of IPF patients.

Conflict of interest: A. Caminati reports personal fees from Roche and Boehringer Ingelheim, outside the submitted work. C. Lonati has nothing to disclose. R. Cassandro has nothing to disclose. D. Elia has nothing to disclose. G. Pelosi has nothing to disclose. O. Torre has nothing to disclose. M. Zompatori has nothing to disclose. E. Uslenghi has nothing to disclose. S. Harari reports grants and personal fees from Roche, Actelion and Boehringer Ingelheim, outside the submitted work.

\section{References}

1 Raghu G, Collard HR, Egan JJ, et al. An official ATS/ERS/JRS/ALAT statement: idiopathic pulmonary fibrosis: evidence-based guidelines for diagnosis and management. Am J Respir Crit Care Med 2011; 183: 788-824.

2 Fernandez Perez ER, Daniels CE, Schroeder DR, et al. Incidence, prevalence, and clinical course of idiopathic pulmonary fibrosis: a population-based study. Chest 2010; 137: 129-137.

3 Vancheri C, Failla M, Crimi N, et al. Idiopathic pulmonary fibrosis: a disease with similarities and links to cancer biology. Eur Respir J 2010; 35: 496-504.

4 Olson AL, Swigris JJ, Lezotte DC, et al. Mortality from pulmonary fibrosis increased in the United States from 1992 to 2003. Am J Respir Crit Care Med 2007; 176: 277-284.

5 Ley B, Collard HR, King TE Jr. Clinical course and prediction of survival in idiopathic pulmonary fibrosis. Am J Respir Crit Care Med 2011; 183: 431-440.

6 King TE Jr, Bradford WZ, Castro-Bernardini S, et al. A phase 3 trial of pirfenidone in patients with idiopathic pulmonary fibrosis. N Engl J Med 2014; 370: 2083-2092. 

integrated analysis of cumulative data from 5 clinical trials. BMJ Open Respir Res 2016; 3: e000105.

Nathan SD, Albera C, Bradford WZ, et al. Effect of pirfenidone on mortality: pooled analyses and meta-analyses of clinical trials in idiopathic pulmonary fibrosis. Lancet Respir Med 2017; 5: 33-41.

9 Noble PW, Albera C, Bradford WZ, et al. Pirfenidone for idiopathic pulmonary fibrosis: analysis of pooled data from three multinational phase 3 trials. Eur Respir J 2016; 47: 243-253.

10 Richeldi L, Costabel U, Selman M, et al. Efficacy of a tyrosine kinase inhibitor in idiopathic pulmonary fibrosis N Engl J Med 2011; 365: 1079-1087.

11 Richeldi L, du Bois RM, Raghu G, et al. Efficacy and safety of nintedanib in idiopathic pulmonary fibrosis. N Engl J Med 2014; 370: 2071-2082.

12 Richeldi L, Cottin V, du Bois RM, et al. Nintedanib in patients with idiopathic pulmonary fibrosis: combined evidence from the TOMORROW and INPULSIS trials. Respir Med 2016; 113: 74-79.

13 Raghu G, Rochwerg B, Zhang Y, et al. An official ATS/ERS/JRS/ALAT clinical practice guideline: treatment of idiopathic pulmonary fibrosis. An update of the 2011 clinical practice guideline. Am J Respir Crit Care Med 2015; 192: 3-19.

14 Lipsi R, Mazzola D, Caminati A, et al. Severe idiopathic pulmonary fibrosis: a clinical approach. Eur J Intern Med 2018; 50: 20-27.

15 Scelfo C, Caminati A, Harari S. Recent advances in managing idiopathic pulmonary fibrosis. F1000Res 2017; 6: 2052 .

16 Johannson KA. Air pollution exposure and IPF: prevention when there is no cure. Thorax 2018; 73: $103-104$.

17 Conti S, Harari S, Caminati A, et al. The association between air pollution and the incidence of idiopathic pulmonary fibrosis in Northern Italy. Eur Respir J 2018; 51: 1700397.

18 Raghu G, Chen SY, Hou Q, et al. Incidence and prevalence of idiopathic pulmonary fibrosis in US adults 1864 years old. Eur Respir J 2016; 48: 179-186.

19 Harari S, Madotto F, Caminati A, et al. Epidemiology of idiopathic pulmonary fibrosis in Northern Italy. PLoS One 2016; 11: e0147072.

20 Raghu G, Amatto VC, Behr J, et al. Comorbidities in idiopathic pulmonary fibrosis patients: a systematic literature review. Eur Respir J 2015; 46: 1113-1130.

21 Hyldgaard C, Hilberg O, Bendstrup E. How does comorbidity influence survival in idiopathic pulmonary fibrosis? Respir Med 2014; 108: 647-653.

22 Behr J, Kreuter M, Hoeper MM, et al. Management of patients with idiopathic pulmonary fibrosis in clinical practice: the INSIGHTS-IPF registry. Eur Respir J 2015; 46: 186-196.

23 Kreuter M, Ehlers-Tenenbaum S, Palmowski K, et al. Impact of comorbidities on mortality in patients with idiopathic pulmonary fibrosis. PLoS One 2016; 11: e0151425.

24 Adir Y, Harari S. Pulmonary hypertension associated with chronic obstructive lung disease and idiopathic pulmonary fibrosis. Curr Opin Pulm Med 2014; 20: 414-420.

25 Harari S, Caminati A. Idiopathic pulmonary fibrosis: from clinical trials to real-life experiences. Eur Respir Rev 2015; 24: 420-427.

26 Jo HE, Glaspole I, Grainge C, et al. Baseline characteristics of idiopathic pulmonary fibrosis: analysis from the Australian Idiopathic Pulmonary Fibrosis Registry. Eur Respir J 2017; 49: 1601592.

27 Wuyts WA, Dahlqvist C, Slabbynck H, et al. Baseline clinical characteristics, comorbidities and prescribed medication in a real-world population of patients with idiopathic pulmonary fibrosis: the PROOF registry. BMJ Open Respir Res 2018; 5: e000331.

28 Collard HR, Ward AJ, Lanes S, et al. Burden of illness in idiopathic pulmonary fibrosis. J Med Econ 2012; 15: 829-835.

29 Mortimer K, Hartmann N, Chan C, et al. Characterizing idiopathic pulmonary fibrosis patients using US Medicare-advantage health plan claims data. PMC Pulm Med 2019; 19: 11.

30 Caminati A, Madotto F, Cesana GC, et al. Epidemiological studies in idiopathic pulmonary fibrosis: pitfalls in methodologies and data interpretation. Eur Respir Rev 2015; 137: 436-444.

31 Ozawa Y, Suda T, Naito T, et al. Cumulative incidence of and predictive factors for lung cancer in IPF Respirology 2009; 14: 723-728.

32 Lee JS, Collard HR, Anstrom KJ, et al. Anti-acid treatment and disease progression in idiopathic pulmonary fibrosis: an analysis of data from three randomized controlled trials. Lancet Respir Med 2013; 1: 369-376.

33 Johannson KA, Strambu I, Ravaglia C, et al. Antacid therapy in idiopathic pulmonary fibrosis: more questions than answers? Lancet Respir Med 2017; 5: 591-598.

34 Tsakiri KD, Cronkhite JT, Kuan PJ, et al. Adult-onset pulmonary fibrosis caused by mutations in telomerase. Proc Natl Acad Sci USA 2007; 104: 7552-7557.

35 Calado R, Young N. Telomeres in disease. F1000 Med Rep 2012; 4: 8.

36 Alder JK, Guo N, Kembou F, et al. Telomere length is a determinant of emphysema susceptibility. Am J Respir Crit Care Med 2011; 184: 904-912.

37 Selman M, Pardo A. Revealing the pathogenic and aging-related mechanisms of the enigmatic idiopathic pulmonary fibrosis. An integral model. Am J Respir Crit Care Med 2014; 189: 1161-1172.

38 Hunt WR, Zughaier SM, Guentert DE, et al. Hyperglycemia impedes lung bacterial clearance in a murine model of cystic fibrosis-related diabetes. Am J Physiol Lung Cell Mol Physiol 2014; 306: L43-L49.

39 Kyung SY, Byun KH, Yoon JY, et al. Advanced glycation end-products and receptor for advanced glycation end-products expression in patients with idiopathic pulmonary fibrosis and NSIP. Int J Clin Exp Pathol 2014; 7: 221-228.

40 Mertens V, Blondeau K, Vanaudenaerde B, et al. Gastric juice from patients “on” acid suppressive therapy can still provoke a significant inflammatory reaction by human bronchial epithelial cells. J Clin Gastroenterol 2010; 44: e230-e235.

41 Kurashima K, Takayanagi N, Tsuchiya N, et al. The effect of emphysema on lung function and survival in patients with idiopathic pulmonary fibrosis. Respirology 2010; 15: 843-848.

42 Ryerson CJ, Hartman T, Elicker BM, et al. Clinical features and outcomes in combined pulmonary fibrosis and emphysema in idiopathic pulmonary fibrosis. Chest 2013; 144: 234-240. 
Mejia M, Carrillo G, Rojas-Serrano J, et al. Idiopathic pulmonary fibrosis and emphysema: decreased survival associated with severe pulmonary arterial hypertension. Chest 2009; 136: 10-15.

Cottin V, Nunes H, Brillet PY, et al. Combined pulmonary fibrosis and emphysema: a distinct under-recognised entity. Eur Respir J 2005; 26: 586-593.

Zhang L, Zhang C, Dong F, et al. Combined pulmonary fibrosis and emphysema: a retrospective analysis of clinical characteristics, treatment and prognosis. BMC Pulm Med 2016; 16: 137.

Schmidt SL, Nambiar AM, Tayob N, et al. Pulmonary function measures predict mortality differently in IPF versus combined pulmonary fibrosis and emphysema. Eur Respir J 2011; 38: 176-183.

Swigris JJ. Towards a refined definition of combined pulmonary fibrosis and emphysema. Respirology 2019; 24 $9-10$.

Cottin V. The impact of emphysema in pulmonary fibrosis. Eur Respir Rev 2013; 22: 153-157.

Cottin V, Hansell DM, Sverzellati N, et al. Effect of emphysema extent on serial lung function in patients with idiopathic pulmonary fibrosis. Am J Respir Crit Care Med 2017; 196: 1162-1171.

Chilosi M, Poletti V, Rossi A. The pathogenesis of COPD and IPF: distinct horns of the same devil? Respir Res 2012; 13: 3.

Raghu G, Wells AU, Nicholson AG, et al. Effect of nintedanib in subgroups of idiopathic pulmonary fibrosis by diagnostic criteria. Am J Respir Crit Care Med 2017; 195: 78-85.

Buendia-Roldan I, Mejia M, Navarro C, et al. Idiopathic pulmonary fibrosis: clinical behavior and aging associated morbidities. Respir Med 2017; 129: 46-52.

Galiè N, Humbert M, Vachiery JL, et al. 2015 ESC/ERS Guidelines for the diagnosis and treatment of pulmonary hypertension: The Joint Task Force for the Diagnosis and Treatment of Pulmonary Hypertension of the European Society of Cardiology (ESC) and the European Respiratory Society (ERS): Endorsed by: Association for European Paediatric and Congenital Cardiology (AEPC), International Society for Heart and Lung Transplantation (ISHLT). Eur Respir J 2015; 46: 903-975.

Nathan SD, Barbera JA, Gaine SP, et al. Pulmonary hypertension in chronic lung disease and hypoxia. Eur Respir J 2019; 53: 1801914.

Simonneau G, Montani D, Celermajer DS, et al. Haemodynamic definitions and updated clinical classification of pulmonary hypertension. Eur Respir J 2019; 53: 1801913.

Nadrous HF, Pellikka PA, Krowka MJ, et al. Pulmonary hypertension in patients with idiopathic pulmonary fibrosis. Chest 2005; 128: 2393-2399.

Lettieri CJ, Nathan SD, Barnett SD, et al. Prevalence and outcomes of pulmonary arterial hypertension in advanced idiopathic pulmonary fibrosis. Chest 2006; 129: 746-752.

Nathan SD, Shlobin OA, Ahmad S, et al. Pulmonary hypertension and pulmonary function testing in idiopathic pulmonary fibrosis. Chest 2007; 131: 657-663.

Shorr AF, Wainright JL, Cors CS, et al. Pulmonary hypertension in patients with pulmonary fibrosis awaiting lung transplant. Eur Respir J 2007; 30: 715-721.

Nathan SD, Shlobin OA, Ahmad S, et al. Serial development of pulmonary hypertension in patients with idiopathic pulmonary fibrosis. Respiration 2008; 76: 288-294. of pulmonary hypertension in idiopathic pulmonary fibrosis. Respir Med 2008; 102: 1305-1310.

Minai OA, Santacruz JF, Alster JM, et al. Impact of pulmonary hemodynamics on 6-min walk test in idiopathic pulmonary fibrosis. Respir Med 2012; 106: 1613-1621.

Rivera-Lebron BN, Forfia PR, Kreider M, et al. Echocardiographic and hemodynamic predictors of mortality in idiopathic pulmonary fibrosis. Chest 2013; 144: 564-570.

Arcasoy SM, Christie JD, Ferrari VA, et al. Echocardiographic assessment of pulmonary hypertension in patients with advanced lung disease. Am J Respir Crit Care Med 2003; 167: 735-740.

Oldham JM, Collard HR. Comorbid conditions in idiopathic pulmonary fibrosis: recognition and management. Front Med 2017; 4: 123.

Castria D, Refini RM, Bargagli E, et al. Pulmonary hypertension in idiopathic pulmonary fibrosis: prevalence and clinical progress. Int J Immunopathol Pharmacol 2012; 25: 681-689.

Harari S, Caminati A, Cassandro R, et al. Pulmonary hypertension in idiopathic pulmonary fibrosis does not influence six-minute walk distance: results from a retrospective study. Sarcoidosis Vasc Diffuse Lung Dis 2014; 31: 297-305.

King TE Jr, Brown KK, Raghu G, et al. BUILD-3: a randomized, controlled trial of bosentan in idiopathic pulmonary fibrosis. Am J Respir Crit Care Med 2011; 184: 92-99.

Raghu G, Behr J, Brown KK, et al. Treatment of idiopathic pulmonary fibrosis with ambrisentan: a parallel, randomized trial. Ann Intern Med 2013; 158: 641-649.

Raghu G, Million-Rousseau R, Morganti A, et al. Macitentan for the treatment of idiopathic pulmonary fibrosis: the randomised controlled MUSIC trial. Eur Respir J 2013; 42: 1622-1632.

Corte TJ, Keir GJ, Dimopoulos K, et al. Bosentan in pulmonary hypertension associated with fibrotic idiopathic interstitial pneumonia. Am J Respir Crit Care Med 2014; 190: 208-217.

Raghu G, Nathan SD, Behr J, et al. Pulmonary hypertension in idiopathic pulmonary fibrosis with mild-to-moderate restriction. Eur Respir J 2015; 46: 1370-1377.

Hoeper MM, Halani $\mathrm{H}$, Wilkens $\mathrm{H}$, et al. Riociguat for interstitial lung disease and pulmonary hypertension: a pilot trial. Eur Respir J 2013; 41: 853-860.

therapies? Chest 2018; 153: 217-223.

Idiopathic Pulmonary Fibrosis Clinical Research Network. A controlled trial of sildenafil in advanced idiopathic pulmonary fibrosis. N Engl J Med 2010; 363: 620-628. fibrosis and right-sided ventricular dysfunction. Chest 2013; 143: 1699-1708.

Kolb M, Raghu G, Wells AU, et al. Nintedanib plus sildenafil in patients with idiopathic pulmonary fibrosis. N Eng J Med 2018; 379: 1722-1731. 
Behr J, Nathan SD, Harari S, et al. Sildenafil added to pirfenidone in patients with advanced idiopathic pulmonary fibrosis and risk of pulmonary hypertension: a phase IIb, randomised, double-blind, placebo-controlled study - rationale and study design. Respir Med 2018; 138: 13-20.

Hubbard R, Venn A, Lewis S, et al. Lung cancer and cryptogenic fibrosing alveolitis. A population-based cohort study. Am J Respir Crit Care Med 2000; 161: 5-8.

Park J, Kim DS, Shim TS, et al. Lung cancer in patients with idiopathic pulmonary fibrosis. Eur Respir J 2001; 17: 1216-1219.

Le Jeune I, Gribbin J, West J, et al. The incidence of cancer in patients with idiopathic pulmonary fibrosis and sarcoidosis in the UK. Respir Med 2007; 101: 2534-2540.

Tzouvelekis A, Gomatou G, Bouros E, et al. Common pathogenic mechanisms between idiopathic pulmonary fibrosis and lung cancer. Chest 2019; 156: 383-391.

Usui K, Tanai C, Tanaka Y, et al. The prevalence of pulmonary fibrosis combined with emphysema in patients with lung cancer. Respirology 2011; 16: 326-331.

Koo HJ, Do KH, Lee JB, et al. Lung cancer in combined pulmonary fibrosis and emphysema: a systematic review and meta-analysis. PLoS One 2016; 11: e0161437.

Tomassetti S, Gurioli C, Ryu JH, et al. The impact of lung cancer on survival of idiopathic pulmonary fibrosis. Chest 2015; 147: 157-164.

Watanabe A, Higami T, Ohori S, et al. Is lung cancer resection indicated in patients with idiopathic pulmonary fibrosis? J Thorac Cardiovasc Surg 2008; 136: 1357-1363.

Suzuki H, Sekine Y, Yoshida S, et al. Risk of acute exacerbation of interstitial pneumonia after pulmonary resection for lung cancer in patients with idiopathic pulmonary fibrosis based on preoperative high-resolution computed tomography. Surg Today 2011; 41: 914-921.

Mizuno Y, Iwata H, Shirahashi K, et al. The importance of intraoperative fluid balance for the prevention of postoperative acute exacerbation of idiopathic pulmonary fibrosis after pulmonary resection for primary lung cancer. Eur J Cardiothorac Surg 2012; 41: e161-e165.

Choi SM, Lee J, Park YS, et al. Postoperative pulmonary complications after surgery in patients with interstitial lung disease. Respiration 2014; 87: 287-293.

Iwata T, Yoshida T, Fujiwara T, et al. Effect of perioperative pirfenidone treatment in lung cancer patients with idiopathic pulmonary fibrosis. Ann Thorac Surg 2016; 102: 1905-1910.

Kenmotsu H, Naito T, Kimura M, et al. The risk of cytotoxic chemotherapy-related exacerbation of interstitial lung disease with lung cancer. J Thorac Oncol 2011; 6: 1242-1246.

Ono T, Hareyama M, Nakamura T, et al. The clinical results of proton beam therapy in patients with idiopathic pulmonary fibrosis: a single center experience. Radiat Oncol 2016; 11: 56.

Reck M, Kaiser R, Mellemgaard A, et al. Docetaxel plus nintedanib versus docetaxel plus placebo in patients with previously treated non-small-cell lung cancer (LUME-Lung 1): a phase 3, double-blind, randomised controlled trial. Lancet Oncol 2014; 15: 143-155.

Mediavilla-Varela M, Boateng K, Noyes D, et al. The anti-fibrotic agent pirfenidone synergizes with cisplatin in killing tumor cells and cancer-associated fibroblasts. BMC Cancer 2016; 16: 176.

Miura Y, Saito T, Tanaka T, et al. Reduced incidence of lung cancer in patients with lung cancer treated with pirfenidone. Respir Invest 2018; 56: 72-79.

National Lung Screening Trial Research Team. Reduced lung-cancer mortality with low-dose computed tomographic screening. N Engl J Med 2011; 365: 395-409.

Mermigkis C, Chapman J, Golish J, et al. Sleep-related breathing disorders in patients with idiopathic pulmonary fibrosis. Lung 2007; 185: 173-178.

Lancaster LH, Mason WR, Parnell JA, et al. Obstructive sleep apnea is common in idiopathic pulmonary fibrosis. Chest 2009; 136: 772-778.

Mermigkis C, Stagaki E, Tryfon S, et al. How common is sleep-disordered breathing in patients with idiopathic pulmonary fibrosis? Sleep Breath 2010; 14: 387-390.

Mermigkis C, Bouloukaki I, Antoniou K, et al. Obstructive sleep apnea should be treated in patients with idiopathic pulmonary fibrosis. Sleep Breath 2015; 19: 385-391.

Milioli G, Bosi M, Poletti V, et al. Sleep and respiratory sleep disorders in idiopathic pulmonary fibrosis. Sleep Med Rev 2016; 26: 57-63.

Mermigkis C, Bouloukaki I, Schiza SE. Sleep as a new target for improving outcomes in idiopathic pulmonary fibrosis. Chest 2017; 152: 1327-1338.

Schiza S, Mermigkis C, Margaritopoulos GA, et al. Idiopathic pulmonary fibrosis and sleep disorders: no longer strangers in the night. Eur Respir Rev 2015; 24: 327-339.

Sériès F, Cormier Y, Lampron N, et al. Influence of lung volume in sleep apnoea. Thorax 1989; 44: 52-57.

Heinzer RC, Stanchina ML, Malhotra A, et al. Lung volume and continuous positive airway pressure requirements in obstructive sleep apnea. Am J Respir Crit Care Med 2005; 172: 114-117.

Raghu G. The role of gastroesophageal reflux in idiopathic pulmonary fibrosis. Am J Med 2003; 115: 60-64.

Pialoux V, Hanly PJ, Foster GE, et al. Effects of exposure to intermittent hypoxia on oxidative stress and acute hypoxic ventilatory response in humans. Am J Respir Crit Care Med 2009; 180: 1002-1009.

Gille T, Didier M, Boubaya M, et al. Obstructive sleep apnoea and related comorbidities in incident idiopathic pulmonary fibrosis. Eur Respir J 2017; 49: 1601934.

Kizer JR, Zisman DA, Blumenthal NP, et al. Association between pulmonary fibrosis and coronary artery disease. Arch Intern Med 2004; 164: 551-556.

Hubbard RB, Smith C, Le Jeune I, et al. The association between idiopathic pulmonary fibrosis and vascular disease: a population-based study. Am J Respir Crit Care Med 2008; 178: 1257-1261.

Izbicki G, Ben-Dor I, Shitrit D, et al. The prevalence of coronary artery disease in end-stage pulmonary disease: is pulmonary fibrosis a risk factor? Respir Med 2009; 103: 1346-1349.

Nathan SD, Basavaraj A, Reichner C, et al. Prevalence and impact of coronary artery disease in idiopathic pulmonary fibrosis. Respir Med 2010; 104: 1035-1041.

Dalleywater W, Powell HA, Hubbard RB, et al. Risk factors for cardiovascular disease in people with idiopathic pulmonary fibrosis: a population-based study. Chest 2015; 147: 150-156. 
114 Kolilekas L, Manali E, Vlami KA, et al. Sleep oxygen desaturation predicts survival in idiopathic pulmonary fibrosis. J Clin Sleep Med 2013; 9: 593-601.

115 Song JW, Song JK, Kim DS. Echocardiography and brain natriuretic peptide as prognostic indicators in idiopathic pulmonary fibrosis. Respir Med 2009; 103: 180-186.

116 Nathan SD, Weir N, Shlobin OA, et al. The value of computed tomography scanning for the detection of coronary artery disease in patients with idiopathic pulmonary fibrosis. Respirology 2011; 16: 481-486.

117 Suzuki A, Kondoh Y. The clinical impact of major comorbidities on idiopathic pulmonary fibrosis. Respir Investig 2017; 55: 94-103.

118 van Cleemput J, Sonaglioni A, Wuyts WA, et al. Idiopathic pulmonary fibrosis for cardiologists: differential diagnosis, cardiovascular comorbidities and patient management. Adv Ther 2019; 36: 298-317.

119 Karkkainen M, Nurmi H, Kettunen HP, et al. Underlying and immediate causes of death in patients with idiopathic pulmonary fibrosis. BMC Pulm Med 2018; 18: 69.

120 Sode BF, Dahl M, Nielsen SF, et al. Venous thromboembolism and risk of idiopathic interstitial pneumonia: a nationwide study. Am J Respir Crit Care Med 2010; 181: 1085-1092.

121 Sprunger DB, Olson AL, Huie TJ, et al. Pulmonary fibrosis is associated with an elevated risk of thromboembolic disease. Eur Respir J 2012; 39: 125-132.

122 Kubo H, Nakayama K, Yanai M, et al. Anticoagulant therapy for idiopathic pulmonary fibrosis. Chest 2005; 128: $1475-1482$.

123 Noth I, Anstrom KJ, Calvert SB, et al. A placebo-controlled randomized trial of warfarin in idiopathic pulmonary fibrosis. Am J Respir Crit Care Med 2012; 186: 88-95.

124 Kreuter M, Wijsenbeek MS, Vasakova M, et al. Unfavourable effects of medically indicated orally anticoagulants on survival in idiopathic pulmonary fibrosis. Eur Respir J 2016; 47: 1776-1784.

125 Tomassetti S, Ruy JH, Gurioli C, et al. The effect of anticoagulant therapy for idiopathic pulmonary fibrosis in real life practice. Sarcoidosis Vasc Diffuse Lung Dis 2013; 30: 121-127.

126 Lee JS, Song JW, Wolters PJ, et al. Bronchoalveolar lavage pepsin in acute exacerbation of idiopathic pulmonary fibrosis. Eur Respir J 2012; 39: 352-358.

127 Raghu G, Freudenberger TD, Yang S, et al. High prevalence of abnormal acid gastro-oesophageal reflux in idiopathic pulmonary fibrosis. Eur Respir J 2006; 27: 136-142.

128 Savarino E, Carbone R, Marabotto E, et al. Gastro-oesophageal reflux and gastric aspiration in idiopathic pulmonary fibrosis patients. Eur Respir J 2013; 42: 1322-1331.

129 Tobin RW, Pope CE II, Pellegrini CA, et al. Increased prevalence of gastroesophageal reflux in patients with idiopathic pulmonary fibrosis. Am J Respir Crit Care Med 1998; 158: 1804-1808.

130 Ghebre YT, Raghu G. Idiopathic pulmonary fibrosis: novel concepts of proton pump inhibitors as antifibrotic drugs. Am J Respir Crit Care Med 2016; 193: 1345-1352.

131 Lee JS, Ryu JH, Elicker BM, et al. Gastroesophageal reflux therapy is associated with longer survival in patients with idiopathic pulmonary fibrosis. Am J Respir Crit Care Med 2011; 184: 1390-1394.

132 Torrisi SE, Ley B, Kreuter M, et al. The added value of comorbidities in predicting survival in idiopathic pulmonary fibrosis: a multicenter observational study. Eur Respir J 2019; 53: 1801587.

133 Schwarzkopf L, Witt S, Waelscher J, et al. Associations between comorbidities, their treatment and survival in patients with interstitial lung diseases - a claims data analysis. Respir Res 2018; 19: 73.

134 Costabel U, Behr J, Crestani B, et al. Anti-acid therapy in idiopathic pulmonary fibrosis: insights from IMPULSIS-trials. Respir Res 2018; 19: 167.

135 Kreuter M, Raghu G. Gastro-oesophageal reflux and idiopathic pulmonary fibrosis: the heart burn in patients with IPF can no longer be silent. Eur Respir J 2018; 51: 1800921.

136 Kreuter M, Wuyts W, Renzoni E, et al. Antacid therapy and disease outcomes in idiopathic pulmonary fibrosis: a pooled analysis. Lancet Respir Med 2016; 4: 381-389.

137 Kiduff CE, Kounter MJ, Thomas GA, et al. Effect of acid suppression therapy on gastroesophageal reflux acid cough in idiopathic pulmonary fibrosis: an intervention study. Cough 2014; 10: 4.

138 Dutta P, Funston W, Mussop U, et al. Randomized, double-blind, placebo-controlled pilot trial of omeprazole in idiopathic pulmonary fibrosis. Thorax 2019; 74: 346-353.

139 Raghu G, Pellegrini C, Yow E, et al. Laparoscopic anti-reflux surgery for the treatment of idiopathic pulmonary fibrosis (WRAP-IPF): a multicentre, randomized, controlled, phase II study. Lancet Respir Med 2018; 6: 707-714.

140 Schneider C, Jick SS, Bothner U, et al. COPD and the risk of depression. Chest 2010; 137: 341-347.

141 Yohannes AM, Alexopoulos GS. Depression and anxiety in patients with COPD. Eur Respir Rev 2014; 23 : 345-349.

142 Eisner MD, Blanc PD, Yelin EH, et al. Influence of anxiety on health outcomes in COPD. Thorax 2010; 65: 229-234.

143 Yohannes A, Willgoss $\mathrm{T}$, Baldwin $\mathrm{R}$, et al. Depression and anxiety in chronic heart failure and chronic obstructive pulmonary disease: prevalence, relevance, clinical implications and management. Int J Geriatr Psychiatry 2010; 25: 1209-1221.

144 Lee YJ, Choi SM, Lee YJ, et al. Clinical impact of depression and anxiety in patients with idiopathic pulmonary fibrosis. PLoS One 2017; 12: e0184300.

145 Ozalevli S, Karaali HK, Ilgin D, et al. Effect of home-based pulmonary rehabilitation in patients with idiopathic pulmonary fibrosis. Multidiscip Respir Med 2010; 5: 31-37.

146 Kozu R, Senjyu H, Jenkins SC, et al. Differences in response to pulmonary rehabilitation in idiopathic pulmonary fibrosis and chronic obstructive pulmonary disease. Respiration 2011; 81: 196-205.

147 Caminati A, Cassandro R, Harari S. Pulmonary hypertension in chronic interstitial lung diseases. Eur Respir Rev 2013; 22: 292-301.

148 Dowman L, Hill CJ, Holland AE. Pulmonary rehabilitation for interstitial lung disease. Cochrane Database Syst Rev 2014; 10: CD006322.

149 Huppmann P, Sczepanski B, Boensch M, et al. Effects of inpatient pulmonary rehabilitation in patients with interstitial lung disease. Eur Respir J 2013; 42: 444-453.

150 Ferrara G, Luppi F, Birring SS, et al. Best supportive care for idiopathic pulmonary fibrosis: current gaps and future directions. Eur Respir Rev 2018; 27: 170076. 